\title{
PENGARUH PENAMBAHAN KOLOM TANAH SEMEN TERHADAP PERPINDAHAN VERTIKAL TANAH DASAR EKSPANSIF SAAT KONDISI MENGEMBANG.
}

\author{
Sigiet Arief Wijanarko', Dr. Bambang Setiawan, S.T., M.T ${ }^{2}$, Ir. Noegroho Djarwanti, M.T³ \\ Program Studi Teknik Sipil Fakultas Teknik Universitas Sebelas Maret Surakarta, \\ sigiet.aw@gmail.com \\ Program Studi Teknik Sipil Fakultas Teknik Universitas Sebelas Maret Surakarta, \\ bbstw88@yahoo.co.id \\ Program Studi Teknik Sipil Fakultas Teknik Universitas Sebelas Maret Surakarta, \\ noegroho di@yahoo.com
}

\begin{abstract}
Abstrak
Tanah ekspansif merupakan tanah yang akan mengalami kembang susut bila terjadi perubahan kadar air. Tanah akan mengembang pada musim penghujan dan menyusut saat kering pada musim kemarau. Volume tanah yang mengembang saat kondisi basah dan menyusut dalam kondisi kering akan mengakibatkan bangunan cepat rusak, baik oleh pergeseran, pendorongan maupun penaikan konstruksi bangunan. Tujuan dari penelitian ini adalah untuk mengetahui pengaruh penambahan kolom tanah semen terhadap perpindahan vertikal tanah dasar ekspansif saat kondisi mengembang, sehingga dapat mengetahui besarnya reduksi yang terjadi. Metode penelitian yang digunakan yaitu model fisik skala kecil di laboratorium. Sampel tanah dibedakan menjadi 2 macam variasi yaitu: tanah ekspansif tanpa perkuatan dan dengan perkuatan kolom tanah semen. Pengujian dilakukan dengan mengaliri sampel dengan air selama 28 hari pembasahan setiap pagi dan sore hari. Dial gauge sebanyak 5 buah diletakkan di atas pelat untuk membaca besarnya perpindahan vertikal yang terjadi saat uji pengembangan. Proving ring juga diletakkan diatas plat untuk mengetahui besarnya gaya pengembangan yang menyebabkan plat terdorong keatas. Hasil penelitian menunjukan bahwa penambahan perkuatan kolom tanah semen, mampu mereduksi perpindahan vertikal yang terjadi sebesar 30,44\% hingga 75,47 \% serta mampu mereduksi gaya pengembangan sebesar 20,00 \% hingga 84,01\%.
\end{abstract}

Kata kunci : tanah ekspansif, gaya pengembangan, kolom tanah semen.

\begin{abstract}
Expansive soil is a soil which will experience shrinkage when there is a change in water content. The soil will expand in the rainy season and shrink. when dry in the dry season. The volume of soil that expands during wet conditions and shrinks in dry conditions will result in rapidly damaged buildings, either by shifting, pushing and vertikal moving building construction. The purpose of this research is to know the influence of soil cement column adding treatment to vertical movements of subgrade expansive soils in swelling condition, so it can know the amount of reduction that happened. The research method used is a small-scale physical model in the laboratory. The soil sample is divided into 2 kinds of variation, namely: expansive land without reinforcement and with reinforcement of soil cement column. Testing is done by flowing samples with water for 28 days wetting every morning and evening. A 5 gauge dial is placed on the plate to read the magnitude of the vertical displacements occurring during the swelling test. Proving ring is also placed on the plate to determine the size of the swelling force that causes the plate to push upwards. The results showed that the addition of reinforcement of soil cement column, capable of reducing the vertical moved that occurred at $30.44 \%$ to $75.47 \%$ and able to reduce the development force of $20.00 \%$ to $84.01 \%$.
\end{abstract}

Keywords: expansive soils, swelling force, soil cement column

\section{PENDAHULUAN}

Tanah merupakan material yang sangat erat hubungannya dengan konstruksi sipil. Tanah juga memiliki pengaruh yang besar terhadap pekerjaan konstruksi, maka tanah menjadi komponen yang sangat diperhatikan dalam perencanaan konstruksi. Penyelidikan terhadap karakteristik dan kekuatan tanah terutama sifat- sifat tanah yang mempengaruhi kapasitas dukung tanah dalam menahan beban konstruksi yang ada di atasnya harus dilakukan sebelum melakukan pekerjaan sipil lainnya. Jenis tanah yang sering menimbulkan permasalahan konstruksi antara lain tanah ekspansif. Tanah ini memiliki karakteristik yang unik, yakni mempunyai kemampuan untuk mengembang dan menyusut (sbrink- swell phenomena) yang besar akibat perubahan kondisi kadar airnya. Pembebanan di atas tanah dengan jenis seperti ini, misalnya oleh suatu konstruksi ringan dan jalan raya, akan menimbulkan banyak permasalahan. Volume tanah yang mengembang saat kondisi basah dan menyusut dalam kondisi kering akan mengakibatkan bangunan cepat rusak, baik oleh pergeseran, pendorongan maupun penaikan konstruksi bangunan. Kondisi ini menyebabkan bangunan akan rusak sebelum mencapai umur rancangannya sehingga membutuhkan biaya pemeliharaan tambahan. Perkuatan pada tanah dasar ekspansif sudah banyak 
dilakukan, diantaranya dengan Geotektile, Cerucuk Bambu, dan Cakar Ayam Modifikasi. Perkuatan menggunakan kolom tanah semen atau soil cement column salah satu alternatif yang bisa digunakan untuk memperkuat tanah dasar ekspansif. Perkuatan ini diharapkan mampu memperkuat tanah dasar ekspansif dan mengurangi besar pengembangannya, sehingga dapat mengurangi dampaknya terhadapan perkerasan jalan.

\section{TINJAUAN PUSTAKA}

Penelitian tentang perkuatan tanah ekspansif telah banyak dilakukan dengan model skala kecil, salah satunya adalah penelitian Setiawan (2015) tentang Sistem Cakar Ayam Modifikasi (CAM) untuk mereduksi perpindahan vertikal pada tanah dasar ekspansif. Hasil penelitian menunjukkan bahwa dengan menggunakan Sistem CAM dapat mereduksi perpindahan vertikal akibat tanah dasar ekspansif mengembang, reduksi berkisar 59,46\% hingga 89,64\%. Cakar berfungsi sebagai angkur (paku) dan pemberat, sehingga pelat akan tertahan pada saat pengembangan tanah dasarnya. Penelitian lanjutan mengenai perkuatan tanah dasar menggunakan penambahan kolom dengan berbagai variasi material yang digunakan, telah dilakukan oleh Khotob dkk (2016). Khotob dalam penelitiannya tentang penambahan kolom dengan material tanah-semen sebagai perkuatan tanah dasar menggunakan metode deep soil mix (DSM). Hasil penelitian menunjukan dengan penambahan kolom menunjukan peningkatan daya dukung pada tanah dasar. Penelitian lain mengenai variasi jarak dan panjang kolom stabilisasi tanah lempung ekspansif dengan $15 \%$ fly ash menggunakan metode deep soil mixing. Nilai pengembangan (swelling) pada tanah asli adalah 4,283\%. Pada saat diberikan kolom deep soil mix, nilai swelling berkurang. Tambahan panjang kolom deep soil mix akan memberikan penurunan nilai swelling pada tanah lempung ekspansif.

\section{LANDASAN TEORI}

\section{Identifikasi Tanah Ekspansif}

Pengidentifikasian tanah ekspansif pada awal penyelidikan tanah, diperlukan untuk melakukan metode pengujian yang tepat di laboratorium. Identifikasi tanah ekspansif menggunakan metode Chen 1998 dalam Hardiyatmo 2014. Chen mengemukakan dua cara dalam melakukan identifikasi tanah ekspansif. Cara pertama mempergunakan indeks tunggal, yaitu Plasticity Index (PI). Cara kedua, mempergunakan korelasi antara fraksi lempung lolos saringan no. 200 dan batas cair (LL).

\section{Metode Deep Soil Mixing}

Deep Soil Mix (DSM) merupakan metode pencampuran tanah dengan bahan additive dengan panjang melebihi 30 $\mathrm{m}$. Metode DSM dilapangan menggunakan bantuan crane yang dilengkapi auger hidrolik yang dapat menyemprotkan bahan additive pada ujung dan sisi auger. Proses pencampuran diawali dengan pengeboran pada titik yang telah direncanakan pada panjang tertentu, setelah panjang yang diinginkan tercapai dilanjutkan dengan proses penyampuran bahan additive dengan cara menyemprotkan bahan additive pada auger dengan putaran terbalik dengan kecepatan yang lebih tinggi sambil menarik auger ke atas.

\section{METODE PENELITIAN}

\section{Tahap Persiapan}

Tahap persiapan diperlukan guna memperlancar kegiatan penelitian yang akan dilaksanakan di Laboratorium. Tahap persiapan tersebut berupa tahap persiapan benda uji, persiapan media tanah, persiapan bak pengujian dan perforated pipe.

Tahap Penelitian utama

Penelitian ini bertujuan untuk melihat perilaku secara fisik pengaruh penambahan soil cement column tersebut. Penambahan ini akan mempengaruhi besarnya perpindahan vertikal dan diharapkan dapat mereduksi perpindahan vertical pada plat akibat proses pembasahan tanah ekspansif. Tahap penelitian utama meliputi pekerjaan-pekerjaan antar lain sebagai berikut :

a. Pembuatan sampel tanah pada bak pengujian

1. Persiapan kotak uji yang sudah diberi sekat

2. Memasukkan campuran pasir kerikil hingga ketebalan $5 \mathrm{~cm}$ kemudian ditumbuk hingga padat. Fungsi lapisan ini sebagai drainase

3. Meletakan saringan tipis sepanjang saluran drainase sebagai pembatas agar kerikil dan tanah tidak tercampur

4. Tanah lapisan pertama dimasukkan kedalam kotak uji dengan cara dihamparkan merata dan dipadatkan sedikit demi sedikit hingga dicapai kepadatan yang merata. Pipa drainase (perforated pipe) diletakkan diatas 
tanah lapisan pertama yang berfungsi sebagai penambahan air saat proses pembasahan. Pipa direkatkan pada dinding dengan menggunakan lakban agar tidak berubah posisi saat proses pengurugan

5. Pengurugan dilanjutkan secara merata sesuai dengan ketinggian yang dikehendaki, sambil terus dipadatkan agar didapatkan kepadatan yang merata.

\section{b. Pemasangan perkuatan soil cement column}

Setelah media tanah selesai dipadatkan, diberikan perkuatan soil cement column dengan metode deep soil mixing (DSM). Konfigurasi pemasangan soil cement column pada bak pengujian ditunjukan oleh Gambar 1 berikut :

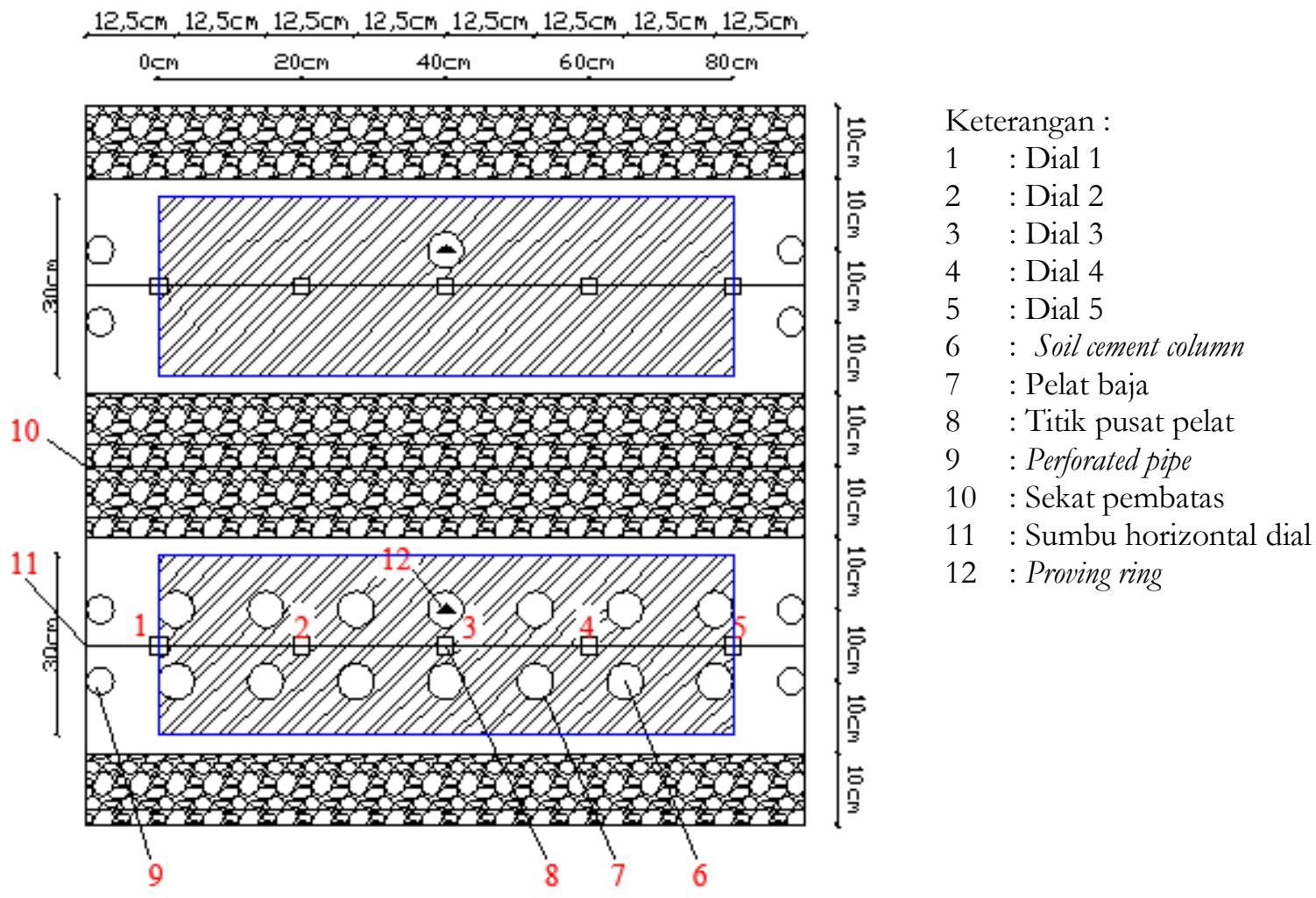

Gambar 1 Sketsa bak pengujian tampak atas

Gambar 1 menunjukkan konfigurasi pemasangan perkuatan soil cement column pada bak pengujian. Setelah didiamkan selama satu minggu, kolom akan cukup keras dan siap untuk dilakukan uji pengembangan.

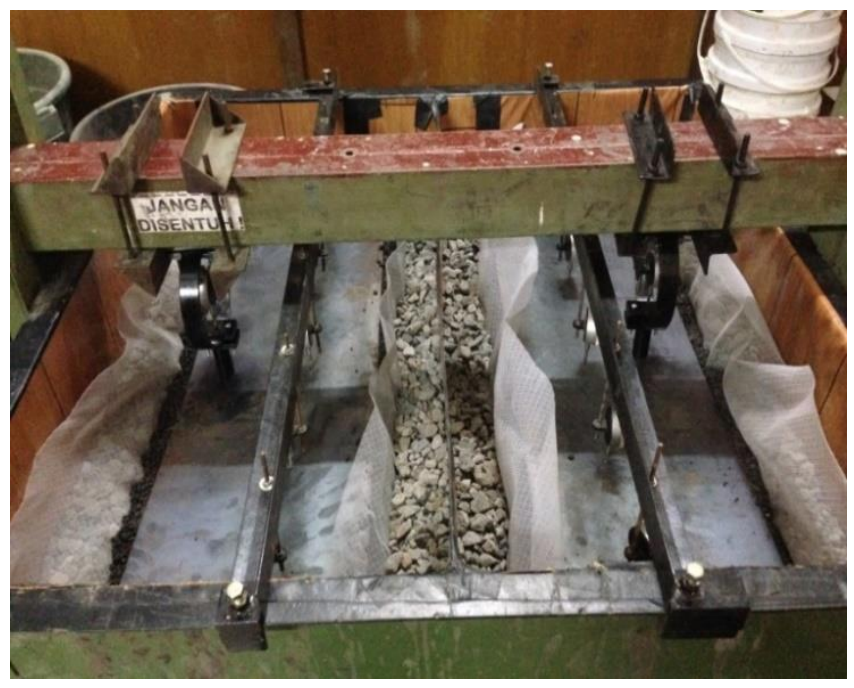

Gambar 2 Bak pengujian tampak atas

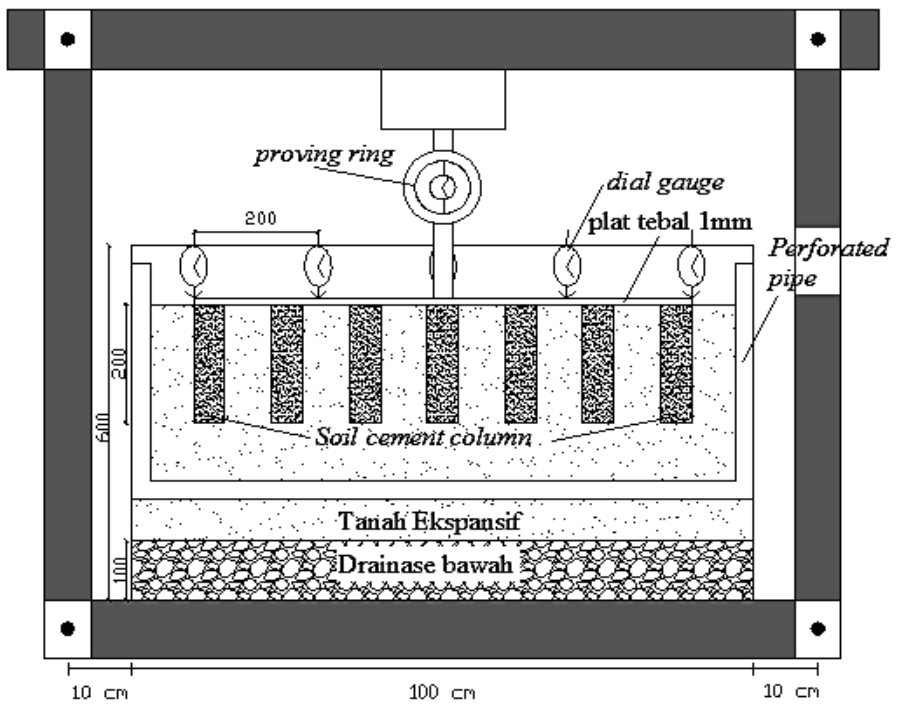

Gambar 3 Potongan melintang bak pengujian

Gambar 2 menunjukkan bak pengujian yang siap dilakukan uji pengembangan tampak atas sedangkan Ganbar 3 menunjukkan potongan melintang bak pengujian.

\section{c. Uji Pengembangan}


Uji pengembangan dilakukan untuk mengetahui besarnya perpindahan vertikal yang terjadi pada plat. Sampel tanah terus di aliri air setiap pagi dan sore hari selama pengamatan berlangsung. Tanah yang telah mengembang karena pengaruh kadar air, akan mendorong plat besi keatas sehingga akan menggerakkan dial gange. Angka yang terbaca pada dial gauge merupakan nilai perpindahan vertikal yang terjadi akibat perubahan kadar air pada tanah sampel. Tahap uji pengembangan meliputi pekerjaan-pekerjaan antara lain sebagai berikut :

1. Plat besi dengan tebal $1 \mathrm{~mm}$, panjang $80 \mathrm{~mm}$, dan lebar $30 \mathrm{~mm}$ diletakkan diatas tanah yang akan diuji.

2. Pemasangan dial gange dilakukan pada lima titik yang sudah ditandai pada besi penopang dial. Dial gange yang digunakan sebanyak 5 buah dan dipasang dengan jarak tiap dial yaitu $0,2 \mathrm{~m}$.

3. Pemasangan proving ring dilakukan dengan cara mengaitkan alat pada tiang penyangga secara kaku, sehingga tidak terjadi pergerakan selama pengujian

4. Pembasahan dilakukan dengan menyiram permukaan tanah di sisi luar model pelat, serta melalui pipa drainase.

5. Pembacaan dilakukan kurang lebih hingga terbaca proses mengembangnya mengalami penurunan, yang kemudian dinyatakan berhenti.

\section{PEMBAHASAN}

\section{a. Perpindahan Vertikal}

Perpindahan vertikal yang terjadi setelah pembasahan pada kedua kondisi menunjukan perubahan yang cukup signifikan. Keduanya hampir memiliki kesamaan yakni proses pengembangan mulai mengalami penurunan pada hari ke 18. Berdasarkan keadaan tersebut, maka perhitungan data hanya dilakukan hingga hari ke-18 pengamatan. Nilai perpindahan vertikal selama 18 hari pengamatan disajikan pada Tabel 1.

Tabel 1 Perpindahan vertikal selama 18 hari

\begin{tabular}{cccccccccccc}
\hline & \multicolumn{10}{c}{ Nerpindahan vertikal (mm) } \\
\cline { 3 - 12 } & & \multicolumn{1}{c}{ Tanpa perkuatan, nomer titik } & \multicolumn{7}{c}{ Dengan perkuatan, nomer titik } \\
\cline { 2 - 12 } & & 1 & 2 & 3 & 4 & 5 & 1 & 2 & 3 & 4 & 5 \\
\hline 1 & 3 & 7,24 & 5,68 & 2,64 & 6,01 & 6,95 & 7,12 & 5,4 & 2,91 & 3,04 & 9,92 \\
\hline 2 & 6 & 20,08 & 13,42 & 8,14 & 14,97 & 20,39 & 19,53 & 13,76 & 5,2 & 7,66 & 18,72 \\
\hline 3 & 9 & 29,04 & 19,24 & 12,43 & 22,74 & 28,94 & 26,83 & 18,24 & 6,26 & 13,24 & 25,85 \\
\hline 4 & 12 & 38,61 & 25,56 & 16,79 & 29,46 & 36,47 & 29,75 & 22,84 & 6,74 & 17,11 & 31,51 \\
\hline 5 & 15 & 49,33 & 32,53 & 23,48 & 38,63 & 48,96 & 33,56 & 26,39 & 6,97 & 19,33 & 39,33 \\
\hline 6 & 18 & 68,63 & 46,76 & 33,02 & 54,62 & 67,73 & 40,71 & 30,12 & 8,1 & 22,11 & 47,11 \\
\hline & & & & & & & & & &
\end{tabular}

Tabel 1 menunjukkan nilai perpindahan vertikal selama 18 hari pengamatan pada tanah dasar ekspansif tanpa perkuatan dan dengan menggnakan perkuatan soil cement column. Berdasarkan tabel tersebut, didapatkan grafik perpindahan vertikal yang ditunjukan pada Gambar 4 (a) dan Gambar 4 (b).

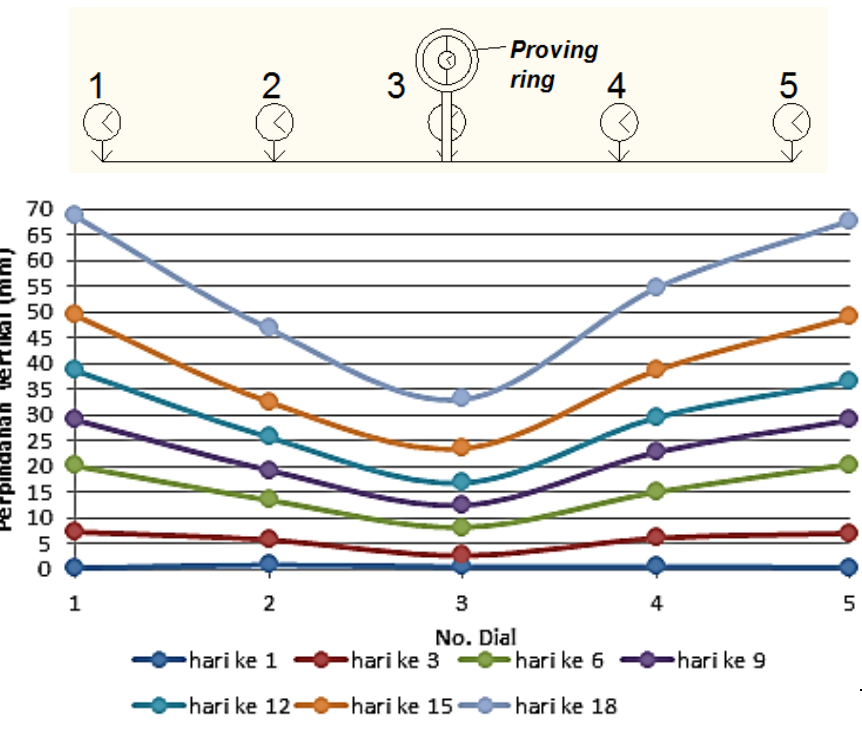

(a)

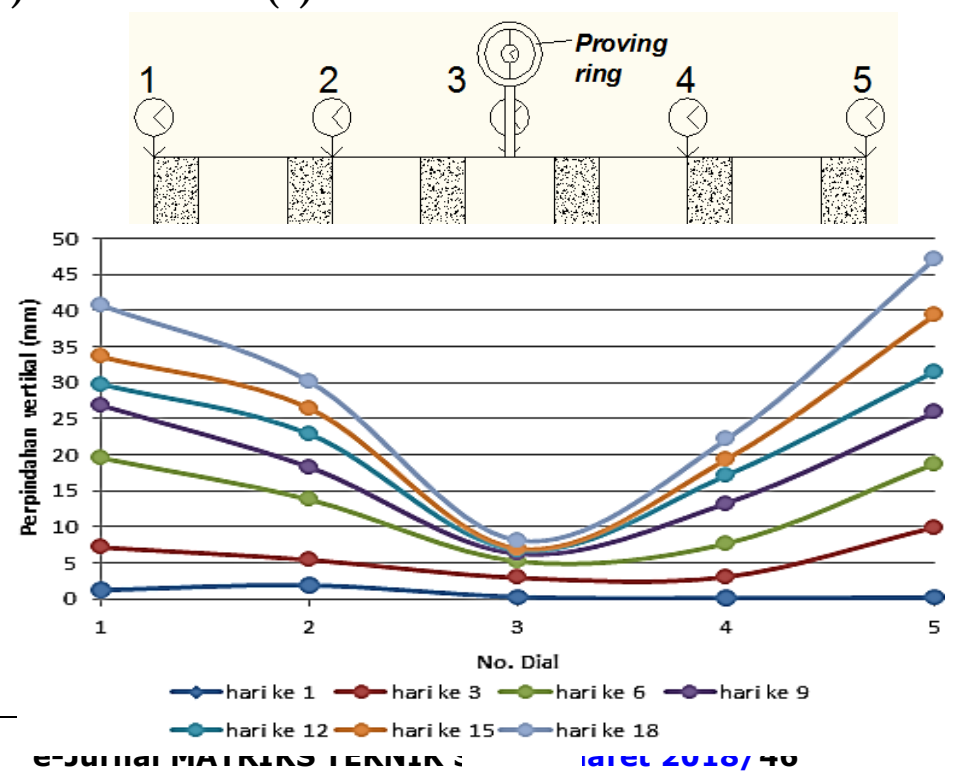

(b) 
Gambar 4 Perpindahan vertikal tanah dasar tanpa perkuatan (a), Perpindahan vertikal menggunakan perkuatan soil cement column (b)

Tampak plat melengkung membentuk pola setengah lingkaran. Terdapat perbedaan tinggi vertikal yang signifikan apabila dibandingkan dengan tanah dasar yang sudah diberi perkuatan soil cement column. Besarnya perpindahan vertikal mengalami penurunan pada Gambar 4 (b). Hal ini membuktikan bahwa perkuatan soil cement column mampu mereduksi besarnya perpindahan vertikal. Besarnya reduksi perpindahan vertikal ditunjukan pada Tabel 2 berikut ini :

Tabel 2 Reduksi perpindahan vertikal

\begin{tabular}{|c|c|c|c|}
\hline \multirow{2}{*}{ Dial } & \multicolumn{2}{|c|}{ Perpindahan vertikal (mm) } & \multirow{2}{*}{$\begin{array}{c}\text { Reduks } \\
(\%)\end{array}$} \\
\hline & Tanpa perkuatan & Soil cement column & \\
\hline 1 & 68,63 & 40,71 & 40,68 \\
\hline 2 & 46,76 & 30,12 & 35,59 \\
\hline 3 & 33,02 & 8,1 & 75,47 \\
\hline 4 & 54,62 & 22,11 & 59,52 \\
\hline 5 & 67,73 & 47,11 & 30,44 \\
\hline
\end{tabular}

Tabel 2 menunjukan reduksi perpindahan vertikal setelah tanah diberi perkuatan soil cement column. Persentase reduksi berdasarkan penurunan perpindahan vertikal setelah tanah diberi perkuatan soil cement column.

\section{b. Gaya Pengembangan}

Gaya pengembangan merupakan besarnya gaya dorong ke atas oleh tanah dasar ekspansif yang mengembang. Gaya pengembangan dihitung berdasarkan nilai baca pada dial gange yang terdapat pada proving ring dikalikan dengan faktor koreksi proving ring. Faktor koreksi yang digunakan pada proving ring yakni 2,4294 pound/div.

Besarnya gaya pengembangan yang terjadi pada tanah dasar selama 18 hari pengamatan ditunjukan pada Gambar 5 berikut :
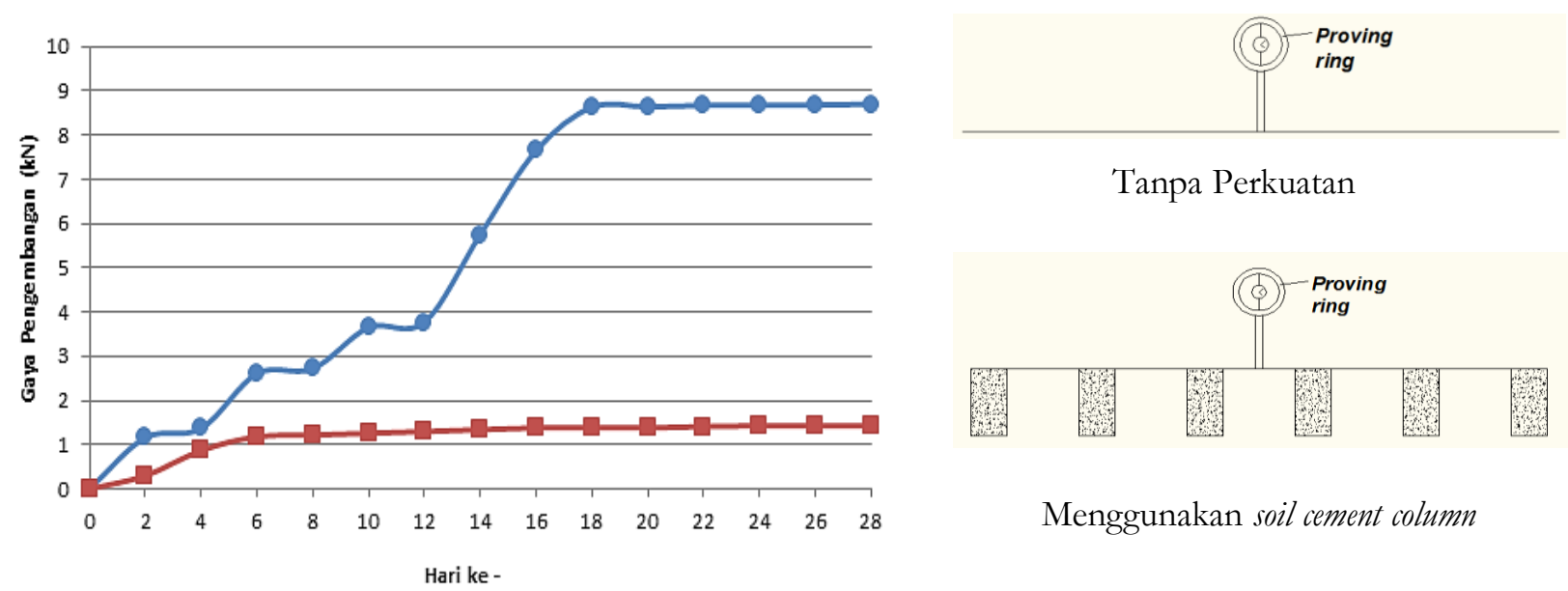

Tanpa Perkuatan

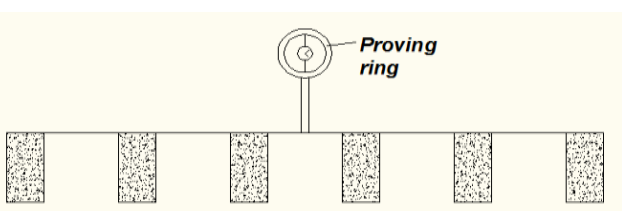

Menggunakan soil cement column

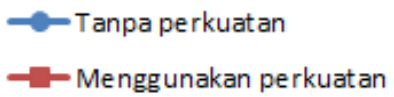

Gambar 5 Gaya pengembangan

Gambar 5 menunjukkan besarnya gaya pengembangan selama pengamatan pada tanah dasar tanpa perkuatan dan dengan menggunakan perkuatan soil cement column. Perbandingan gaya pengembangan pada kedua sampel menunjukkan perubahan yang signifikan. Tanah dasar yang sudah diberi perkuatan soil cement column mampu menahan gaya keatas tanah dasar sehingga berpengaruh juga pada perpindahan vertikal tanah dasar. Besarnya reduksi gaya pengembangan setelah tanah dasar diberi perkuatan soil cement column dapat dilihat pada Tabel 3 berikut : 
Tabel 3 Reduksi Gaya Pengembangan

\begin{tabular}{cccc}
\hline \multirow{2}{*}{ Hari ke- } & \multicolumn{2}{c}{ Gaya pengembangan $(\mathrm{kN})$} & \multirow{2}{*}{$\begin{array}{c}\text { Reduksi } \\
\mathbf{( \% )}\end{array}$} \\
\cline { 2 - 3 } & Tanpa perkuatan & Soil cement column & 20,00 \\
\hline 1 & 0,0607 & 0,0486 & 51,18 \\
\hline 3 & 1,5427 & 0,7531 & 54,79 \\
\hline 6 & 3,1704 & 1,4333 & 65,84 \\
\hline 9 & 4,4094 & 1,5062 & 65,52 \\
\hline 12 & 4,5795 & 1,5791 & 79,82 \\
\hline 15 & 8,1872 & 1,6520 & 84,01 \\
\hline 18 & 10,4831 & 1,6763 & \\
\hline
\end{tabular}

Tabel 3 menunjukan reduksi gaya pengembangan setelah tanah diberi perkuatan soil cement column. Persentase reduksi berdasarkan penurunan gaya pengembangan setelah tanah diberi perkuatan soil cement column.

\section{KESIMPULAN}

1. Penambahan perkuatan tanah dasar berupa Soil Cement Column dapat mereduksi perpindahan vertikal akibat tanah dasar ekspansif yang mengembang, reduksi paling kecil terletak sebesar 30,44\% dan reduksi terbesar sebesar $75,47 \%$.

2. Besarnya gaya pengembangan tanah dasar ekspansif juga mengalami penurunan. Reduksi sebesar $20,00 \%$ pada hari pertama pengamatan dan $84,01 \%$ pada hari ke 18 pengamatan

\section{REFERENSI}

Hardiyatmo, H.C, 2010. Mekanika Tana h I. Yogyakarta: Gajah Mada University Press.

Hardiyatmo, H.C, 2014. Tanah Ekspansif Permasalahan dan Penanganan. Yogyakarta: Gajah Mada University Press.

Kementerian Pekerjaan Umum Direktorat Jenderal Bina Marga. 2013. Manual Desain Perkerasan Jalan Nomor 02/M/BM/2013. Jakarta.

Khotob, A. U. I, "Perilaku Penambahan Soil Mixing Column sebagai Perkuatan Pada Tanah Dasar (Subgrade) Lunak", Skripsi, Program Studi Teknik Sipil. Universitas Sebelas Maret, Surakarta, 2016.

Putranto, A. S, dkk, Pengaruh Variasi Jarak dan Panjang Kolom Stabilisasi Tanah Lempung Ekspansi di Bojonegoro dengan 15\% Fby Ash Menggunakan Metode Deep Soil Mixing Berpola Single Square Terhadap Daya Dukung Tanah, Jurnal Teknik Sipil Fakultas Teknik Universitas Brawijaya, 2015

Setiawan, B, "Perilaku Sistem Cakar Ayam Modifikasi pada Tanah Ekspansif”, Disertasi, Program Studi Teknik Sipil dan Lingkungan. Universitas Gadjah Mada, Yogyakarta, 2015. 